Perspective

\title{
Examining the association between traumatic brain injury and headache
}

\author{
Mohammad Mofatteh ${ }^{1, *}$ \\ ${ }^{1}$ School of Medicine, Dentistry and Biomedical Sciences, Queen's University Belfast, BT71NN Belfast, UK \\ *Correspondence: mmofatteho1@qub.ac.uk (Mohammad Mofatteh) \\ DOI:10.31083/j.jin2004109
}

This is an open access article under the CC BY 4.0 license (https://creativecommons.org/licenses/by/4.0/). Submitted: 11 September 2021 Revised: 21 October 2021 Accepted: 26 October 2021 Published: 30 December 2021

Traumatic brain injury is a common and major cause of disability and death that might require emergency neurological and neurosurgical interventions. Traumatic brain injury can result in temporary or permanent physical, cognitive and psychological impairments. One of the most common complications associated with traumatic brain injury is post-traumatic headache, associated with significant disability and reduced quality of life. Post-traumatic headache is a public health concern that can affect the long-term outcome of traumatic brain injury patients. Clinical symptoms of post-traumatic headache significantly overlap with common primary headaches such as migraine and tension-type headaches. Beyond neurobiological factors, psychological factors can play crucial roles in the initiation and sustainment of post-traumatic headache. While neurological mechanisms underlying post-traumatic headache remains unknown, different studies suggest various mechanisms such as physical damages to the cranial nerves and neck structure, hyper-sensitization of the pain modulatory pathway, and inflammation as underlying causes for the neurobiology of headache. I explore the hypothesis that traumatic brain injury is associated with headaches. In particular, I provide an overview of the neurobiology of post-traumatic headache, its diagnosis, presenting recent findings on the etiology, explaining similarities and differences between with primary headaches such as migraine and tension-type headache, discuss pharmacological and non-pharmacological interventions for the treatments, as well as emphasising on the psychological importance of post-traumatic headache.

Keywords

Traumatic brain injury; Headache; Post-traumatic headache; Migraine; Tensiontype headache; Neurology

\section{Introduction}

Traumatic brain injury (TBI) is a preventable injury caused by external biomechanical forces exerted on the head. The patient outcome can range from complete recovery to disability and death [1]. Referred to as a "silent epidemic", TBI is estimated to affect sixty-nine million people globally every year [2]. TBI is a source of concern for public health practitioners, care providers, and health policymakers. 1.1\% of the US population alone experience lifelong disabilities as a consequence of TBI [3]. The incidence of TBI can increase sporadically due to injuries sustained during military and combat operations [4], and the majority of TBI patients do not seek hospital treatment for their injuries [5].
TBI can cause direct damage to the brain dura and parenchyma, or it can be a closed-head injury with an intact skull and dura [6]. Multiple clinical factors such as the absence or decreased consciousness, the presence of transient or non-transient neurological symptoms, amnesia (i.e., loss of memory of events after the injury), changes in the mental state and radiological images, including computerized tomography (CT) and magnetic resonance imaging (MRI) are used to classify TBI into mild, moderate and severe [7]. TBI can be divided into subconcussive head trauma, repetitive mild head TBI, post-concussive syndrome, and chronic traumatic encephalopathy [8] (Fig. 1).

Approximately $80-90 \%$ of TBI cases are mild TBI, also known as concussion, which is caused by blunt, nonpenetrating forces, mostly by falls, motor vehicle accidents, sports and violence, with a high incidence rate among males, adolescents and young adults [6,9-11]. While a single test cannot establish the clinical diagnosis, $10-15 \%$ of patients with mild TBI can be diagnosed with post-concussive syndrome [12] if their symptoms persist for more than three months [13]. Although subconcussive head trauma does not result in any obvious clinical symptoms, repetitive mild head TBI is the underlying reason for chronic traumatic encephalopathy [7]. This is a progressive neurodegenerative disorder characterized by the deposition of hyperphosphorylated tau at a depth of sulci among contact sports participants and military veterans [14].

Clinical manifestations associated with TBI can be categorized into three groups of physical, cognitive and psychological symptoms [15-17]. Highly variable physical symptoms associated with mild TBI include nausea, dizziness, vomiting, headache, emotional irritability and, in some cases, loss of consciousness $[11,18,19]$. Cognitive impairments in multiple neuroscientific domains such as learning, memory, attention, processing speed, problem-solving, reasoning, and language are associated with TBI $[20,21]$. Psychological symptoms of TBI include depression, anxiety, post-traumatic stress disorder (PTSD), obsessive-compulsive disorder, panic attack, psychosis and personality changes such as apathy and aggression [22, 23]. Most symptoms in patients experiencing concussions are resolved within 12 weeks of the incidence [7]; however, having underlying psychological and physical 


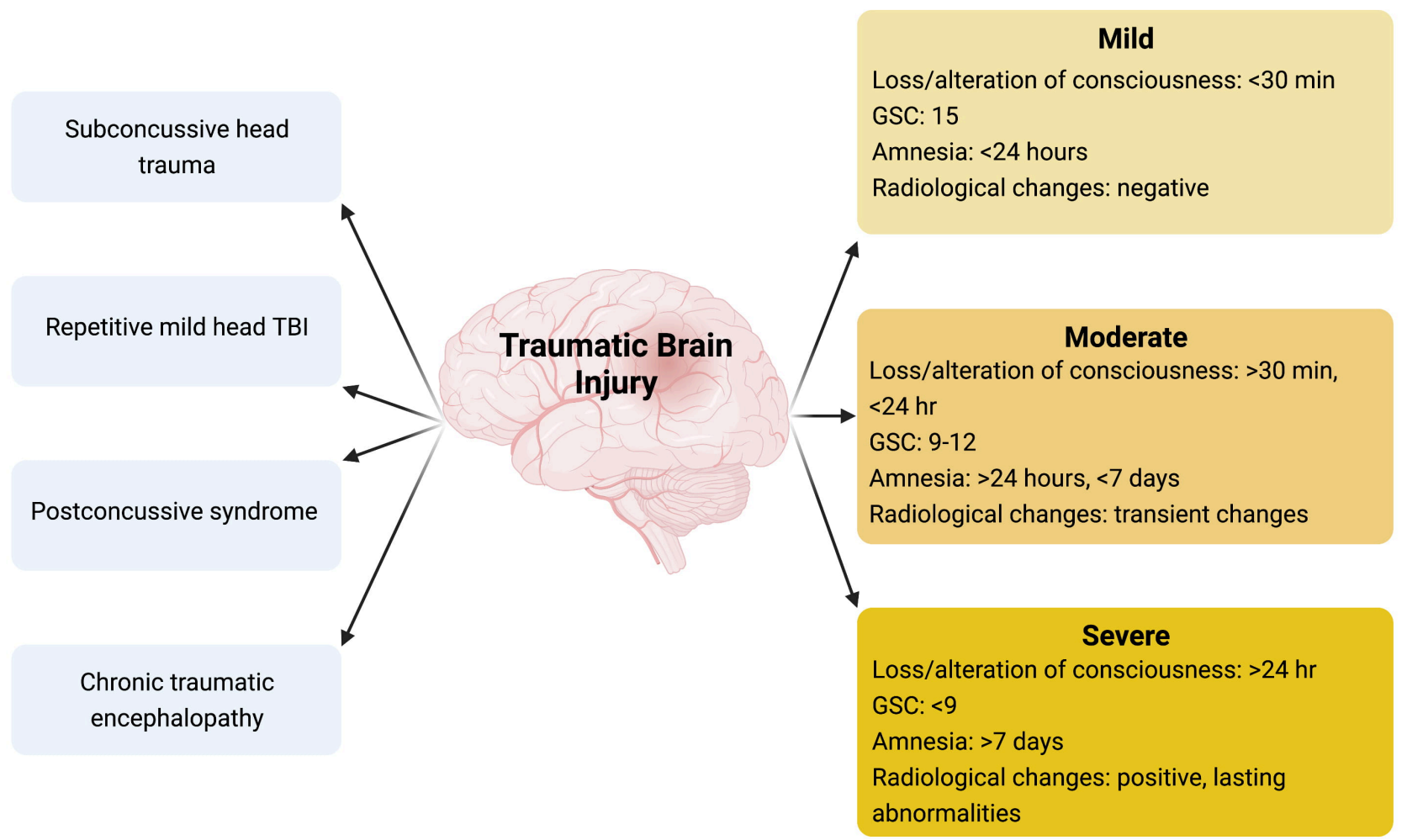

Fig. 1. Traumatic brain injury (TBI) can be classified as mild, moderate and severe based on symptoms manifestation. TBI can also be classified into subconcussive head trauma, repetitive mild head TBI, postconcussive syndrome, and chronic traumatic encephalopathy.

conditions and other factors, such as substance abuse, can prolong the patient's recovery [24, 25].

Headache has been identified as the most common, persistent and debilitating symptom associated with TBI $[19,26]$. TBI patients with post-traumatic headache (PTH) can have poorer outcomes and a longer recovery time than those who do not experience headaches [27, 28]; however, a causal relationship has not been established. PTH patients complain about pain in different head and neck regions, such as temples, forehead, neck, posterior region of the head, eyes, and vertex [29]. Some studies showed that $15 \%$ of TBI patients had headaches three months after the incident [30], while others showed that $90 \%$ of TBI patients suffered from headaches even up to five years after their injury [28, 31]. Variations in the prevalence of PTH can be due to the severity of TBI and type of pain [32, 33].

Comparing TBI to general traumatic injuries, a study reported $18 \%-22 \%$ of PTH patients experienced new or worsened headache symptoms one year after the injury [34], indicating that PTH is not necessarily related to the inciting TBI. Similar studies estimated that between $14 \%-58 \%$ of patients with mild TBI developed headaches 12 months after the trauma $[35,36]$. In contrast, others did not find PTH symptoms after three months in TBI patients compared to controls [37]. Multiple reasons such as the sampling bias, assessment methods, study types, and the country where the study was conducted can potentially explain discrepancies ob- served in PTH prevalence in different studies [26, 38]. For example, one caveat can be the inclusion of TBI patients who had pre-existing headaches in some studies, causing a higher reporting of PTH [39]. A study suggested that variations in reporting the frequency of the post-concussion syndrome could be related to cultural differences [40]. Others corroborated these findings by showing that culture and language background could affect how patients report their symptoms. Therefore, they should be considered in investigating symptoms of post-concussion syndrome [41]. Nevertheless, headaches, especially migraines-like headaches, have negative consequences on the quality of life of individuals experiencing mild TBI $[42,43]$.

PTH may be accompanied by other symptoms and disabilities such as cognitive, behavioral, emotional and somatic impairments [18, 44]. Similarly, chronic primary headaches can be associated with anxiety, depression, suicidal behaviors [45-47], as well as comorbidities such as back pain, ischemic heart disease and stroke [48]. Recent studies demonstrate that the association of psychiatric comorbidities with migraine is complex, and a bidirectional relationship exists between migraine, major depression and panic disorder [49]. Beyond depression, PTH can be associated with other psychiatric disorders such as post-traumatic disorder [50]. 
Table 1. A summary of different studies investigating risk factors associated with PTH. The table provides an overview of the most significant risk factors associated with PTH and is not exhaustive.

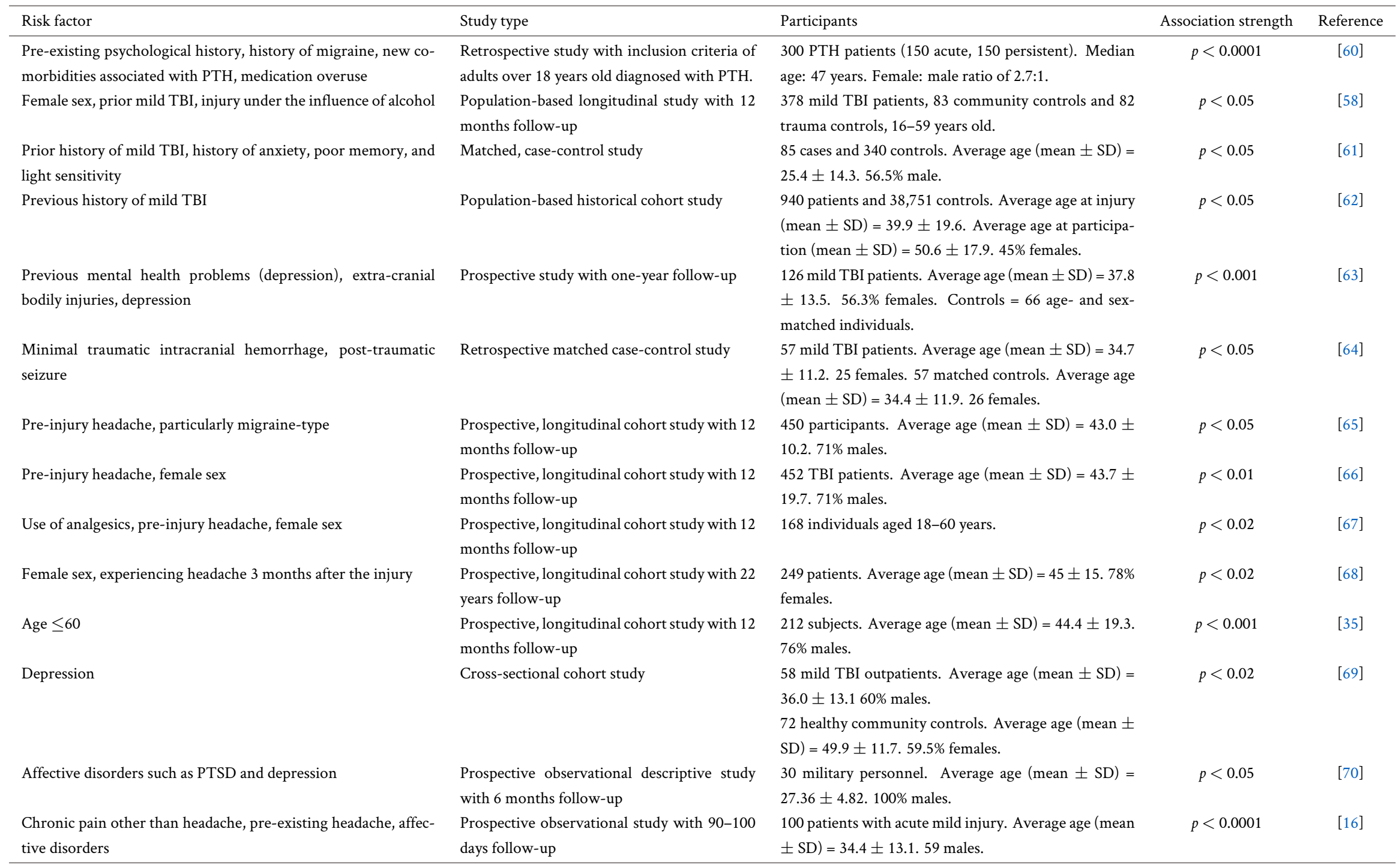


TBI is a major public health concern. It has been estimated that over half of the world's population experience at least one type of TBI over their lifetime [5]. The underlying mechanism of PTH remains unknown, and there is no clear-cut treatment method available. Headache is a common symptom associated with TBI, particularly mild TBI. Individuals can experience different types of headaches as a result of TBI. The reported prevalence of PTH has been variable, ranging from $15 \%$ to $90 \%$ [35].

The presence of headaches is an important factor in the treatment of TBI. Assessment, diagnosis, and management of headache in TBI require robust clinical recommendations and guidelines. A universally accepted protocol is required to be established for the treatment of headaches following TBI. This requires a robust and non-subjective system for the classification of PTH. Identification of biomarkers for PTH can provide an efficient diagnosis to improve prognosis. However, migraine and PTH are differentiated clinically by the presence or absence of biomechanical injury to the head. The majority of patients with PTH present clinical symptoms which are not indistinguishable from migraine.

The exact neuroscientific mechanism contributing to PTH is not comprehensively understood $[49,51]$. While some studies have attempted to identify genes associated with psychiatric disorders and mental health [47], future studies using next-generation sequencing techniques [52] are required to investigate the association between genes and environment to identify genetic risk factors associated with mental health headaches. Beyond neurobiological and cognitive symptoms, the effect of TBI and PTH in other organ systems, such as the gastrointestinal system [53], can be explored to investigate the possibility of behavioral changes, including diet modification to alleviate pain.

\section{Is post-traumatic headache different than other types of headaches?}

The International Classification of Headache Disorders (ICHD) divides headaches into two major categories. Primary headaches such as migraine, tension-type headache, and trigeminal autonomic cephalalgias are considered not to have underlying causes, whereas secondary headaches such as PTH and headaches attributed to vascular and non-vascular cranial disorders, infections and substance withdrawal, etc. are considered to have associated underlying causes [54]. In its latest version, ICHD-III classifies PTH as a secondary headache caused by injury or trauma to the brain, which forms within seven days following the injury, after regaining consciousness and/or after regaining pain sensation and reporting [54]. PTH can be subdivided into acute and persistent headaches. While acute PTH is resolved within three months of experiencing TBI, persistent PTH lasts longer than three months from the incident [39]. PTH can be caused by mild, moderate or severe TBI (Fig. 2) [54]. While PTH is present in all types of TBI, it is most commonly seen in mild TBI [55].

\subsection{Risk factors associated with post-traumatic headache}

Experiencing PTH after mild TBI is quite common, corresponding to $4 \%$ of all secondary headache disorders $[44,56]$. Particularly, patients with mild TBI have a higher prevalence $(72.7 \%-77.9 \%)$ of forming PTH compared to patients with moderate and severe TBI (29.3\%-34.9\%) [55]. Multiple risk factors such as being a female, older age, pre-existing headache, pre-existing psychiatric disorders, experiencing a headache at the medical emergency room, the severity of TBI, medication overuse, and being injured under the influence of alcohol are associated with the development of PTH [29, 34, 57-59]. In contrast, factors such as race, recovery time, the severity of headache, education level, marital status, and Glasgow Coma Scale score are not considered risk factors for PTH $[29,39,59,60]$. A summary of risk factors and predictors associated with PTH is demonstrated in Table 1 (Ref. $[16,35,58,60-70])$.

2.2 Neuropathophysiology of post-traumatic headache: similarities and differences between post-traumatic headache and primary headaches

Resembling different phenotypes associated with primary headaches, PTH is associated with nausea, vomiting, experiencing and/or exacerbating headache after stress, physical activity, light, sound, as well as impaired cognition and psychosocial behaviors [71]. Migraine-like and tension-typelike headaches are the most common headaches associated with PTH $[36,39]$, and other rarer types of headaches such as mixed and cluster-like can be observed as well [71]. Contradicting reports exist on whether PTH is more similar to migraine-like or tension-type-like headaches, indicating the enigmatic nature of PTH. While some studies reported PTH patients have a higher prevalence of migraine-like headaches $[31,35]$, others contradict studies that demonstrated a higher prevalence of tension-type-like headaches [26, 72]. For example, Kjeldgaard et al. [26] showed that $97 \%$ of patients with de novo headaches after experiencing mild TBI had a tensiontype-like headache.

In contrast, Lucas et al. [35] demonstrated that $49 \%$ of patients had a migraine-like headache after experiencing mild TBI. A summary of different types of headaches associated with TBI is shown in Table 2 (Ref. [29]). Multiple factors such as sampling bias, methods used to assess headache, time of evaluation, and classification of PTH can potentially explain some of the variations observed in the data regarding headache types in TBI.

According to the International Headache Society [72], a migraine is an episodic, unilateral, pulsatile headache with nausea, vomiting, photophobia, phonophobia, and worsening symptoms with physical activity. Multiple studies have reported that patients with PTH present clinical symptoms of migraine such as unilateral headache location, throbbing headache, pain exacerbation following physical activities, photophobia and/or phonophobia, nausea and vomiting $[27,31,73-75]$. 


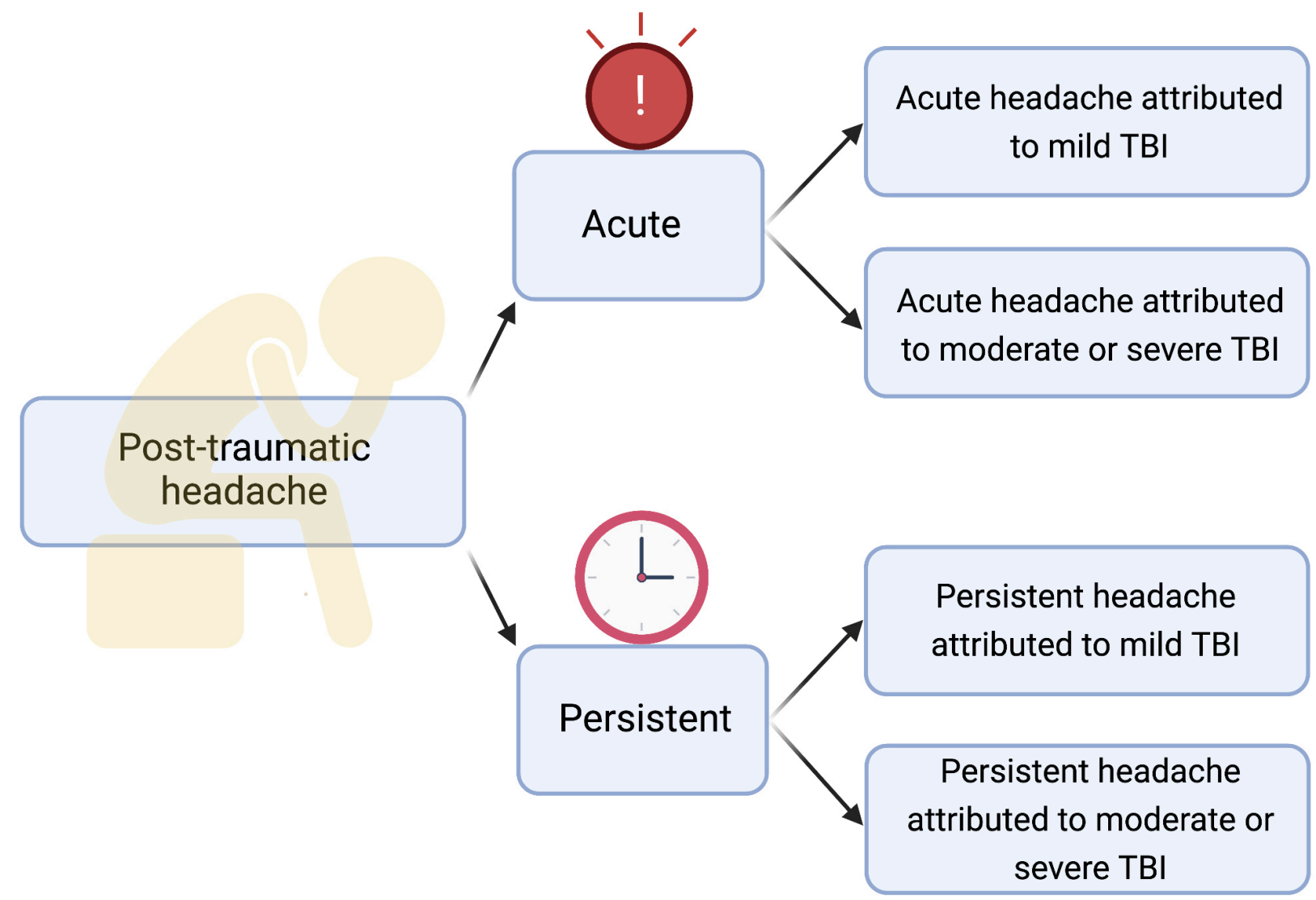

Fig. 2. Classification of acute and persistent headache according to the International Classification of Headache Disorders, 3rd version [54]. Post-traumatic headaches can be divided into acute and persistent. Each category can be subdivided into mild and moderate/severe.

Tension-type headache is the most common neurological disorder in the world [76]. The hallmark of tensiontype headache is its recurrent nature with mild to moderate pain intensity, which tends to be bilateral with pain in the forehead, posterior head regions and neck [77]. Tension-type headache can be distinguished from migraine due to a lack of photophobia, phonophobia and nausea [78]. Based on the frequency of headaches, tension-type headaches can be subdivided into infrequent episodic $(<12$ days with headache/year), frequent episodic $(\geq 12$ and $<180$ days/year) and chronic ( $\geq 180$ days/year) [78]. While infrequent tension-type headaches do not require treatments from physicians, chronic tension-type headaches are challenging to treat and can cause disability [79].

Alternatively, headache alone or associated with cognitive and psychological symptoms can be the only phenotype associated with PTH [80]. Furthermore, persistent PTH can be associated with anxiety, depression, and PTSD $[16,29,44,59]$, sleep disturbance [81], as well as autonomic dysfunction symptoms such as orthostatic intolerance and bladder incontinence [82]. The intensity of PTH can be associated with PTSD [29]. Neurosurgical procedures, such as craniotomy, can mimic PTH, post-craniotomy headaches
[83]. Future research is required to establish the pathogenesis of such headaches and understand whether post-craniotomy headaches can be prevented for successful patient outcomes in neurosurgical procedures.

While its exact etiology remains unknown [56], various changes to the neurophysiology of the brain have been proposed as a potential underlying mechanism of PTH. PTH can be due to direct injury to the tissue during TBI, such as cervical injuries, bone and/or soft tissue trauma, and peripheral nerve damage [29]. Alternatively, indirect consequences of TBI such as pressure palsies, spasticity, deep vein thrombosis, periarticular new bone formation, and abnormal posturing $[29,84]$. Chronic sensitization of nociceptors can also cause PTH $[51,85,86]$.

Inflammation plays a role in the neuroscience of headaches (Fig. 3). Damage to cranial and neck structures can cause neurogenic inflammation resulting in hyperexcitability and hyperactivity of nociceptors [29, 87]. Studies of humans and animal models revealed that TBI could cause the release of cytokines and chemokines to activate and recruit monocytes and facilitate activation of glial cells and release of nociceptive peptides [88-91]. This chain of events, combined with vascular disruption, can cause activation 
Table 2. A summary of clinical characteristics and manifestations of PTH. Some of the information was used from [29].

\begin{tabular}{lllll}
\hline & Migraine-like PTH & Tension-type-like PTH & Cluster-like & Cervicogenic-like \\
\hline Location & Various (unilateral) & Various (bilateral) & $\begin{array}{l}\text { Retro/perito- orbital, with a possi- Originates in the neck and spreads } \\
\text { bility of spreading (unilateral) }\end{array}$ & anteriorly (mainly unilateral) \\
Intensity & Moderate to severe & Mild to moderate & Severe & Mild to severe \\
Quality & Pounding, throbbing, sharp & Pressing, dull & Throbbing & Dull \\
Exacerbation & Physical activity, light, sound Psychological stress, tension & Alcohol consumption & Posture
\end{tabular}

and sensitization of nociceptors to stimuli, resulting in spontaneous pain [91-95]. Mechanical hypersensitivity can also occur in the trigeminal nerve due to myelin sheath deterioration as the result of compression of the nerve by a vein or an artery [96-98]. In parallel, damage to the spinothala$\mathrm{mic} /$ thalamocortical pathway can cause dysfunction of the pain-inhibition pathway, resulting in hyperexcitability and hyperactivity of central neurons [29, 99]. Various damages to the brain, such as diffuse axonal injury, increased release of glutamate, cerebral flow alterations, and widespread neuronal depolarization, are seen in TBI [100-102].

The majority of TBI patients suffer from PTH symptoms that are not distinguishable from migraine symptoms. Such similarities in clinical symptoms of PTH with migraine raises speculations on whether PTH has a specific neuropathophysiology or whether TBI triggers migraine manifested as PTH. Common neuropathological changes exist between migraine and mild TBI, such as an increase in the level of extracellular potassium and intracellular sodium, calcium and chloride $[28,71,101,103-105]$. The frequency and/or intensity of PTH is increased two-fold in patients with migraines who develop PTH $[60,66]$. In contrast, a slight increase in PTH frequency in patients with tension-type headaches $[35,106]$.

Multiple neuroimaging studies have investigated structural [107-110] and functional $[5,98,111,112]$ changes associated with PTH. For example, by studying 54 patients with mild TBI without pre-existing headaches and comparing them to 46 healthy controls, Niu et al. [5] showed that most patients developed PTH up to 12 weeks after their injury. Patients with PTH had a weaker connection between the periaqueductal grey matter in their brainstem, an area responsible for opioid antinociception and the right inferior parietal lobe, which is responsible for self-reference interoception [5]. The strength of the periaqueductal grey connectivity could predict patients' complaints about the impact of PTH on their lives [5]. However, a causal relationship remains the be established. They also suggested that disruption to the functional connectivity of periaqueductal grey matter can be used as a biomarker to identify TBI patients susceptible to developing PTH [5]. Periaqueductal grey is a vulnerable region in mild TBI, especially during accelerationdeceleration forces $[113,114]$.

Previous studies showed that patients with mild TBI were more susceptible to perceiving pain and had a lower threshold for pain. However, the development and maintenance of such pain thresholds could be affected by psychological factors [95]. These findings were corroborated with other studies where patients with PTH had a lower grey matter in the anterior cingulate and dorsolateral prefrontal cortex three months after their injury, and morphological changes were resolved after one year upon cessation of the headache [110]. Additionally, TBI patients with PTH had injuries to their corpus callosum and fornix/septohippocampal circuit [107]. Similar changes in the white matter were observed in patients with migraines [107]. White matter hyperintensity lesions were also associated with less depression in patients with chronic headaches [108]. Indeed, diffuse axonal injury due to shearing forces is a hallmark of TBI and a predictor of the patient outcome $[115,116]$. Previous studies investigated the neuroscience of axon injury and demonstrated injuries to axons and focal lesions due to TBI [116].

Conversely, a history of TBI can accelerate aging and increase the risk of neurodegenerative diseases such as Alzheimer's disease [117]. Axonal injuries can disrupt multiple neuronal functionals, including cargo transportation. Future studies can investigate the role of disruption to motormediated mRNA localization and local translation in neurons of TBI patients [118-120]. Recent studies have proposed the "autonomous clock" idea to control different aspects of organelle biogenesis, such as mitochondria, in cells, autonomous of the cell cycle [121]. Expansion of this idea to neurons can investigate whether regulation of organelle biogenesis in neurons can have any role in therapeutics.

In contrast, a study showed significant differences in the brain of migraine patients and PTH patients without a history of pre-existing headache by comparing regional brain volumes, the thickness of the cortex, brain curvature and surface area [122]. Morphological and structural changes were present in the right supramarginal gyrus, right lateral orbitofrontal lobe, left precuneus, left causal middle frontal lobe and left superior frontal lobe [122]. Similarly, by comparing 33 TBI patients with PTH with healthy controls, Chong et al. [109] demonstrated that PTH patients had a less cortical thickness in the right hemisphere parietal and bilateral frontal regions, indicating morphological changes in the brain associated with PTH.

Major differences in static and dynamic functional connectivity exist between migraine and PTH [112]. Furthermore, distinct structural differences are present in the brain of patients with migraines compared to PTH patients, indicating unique morphological changes that can occur in TBI. By comparing regional volume, cortical thickness, and sur- 


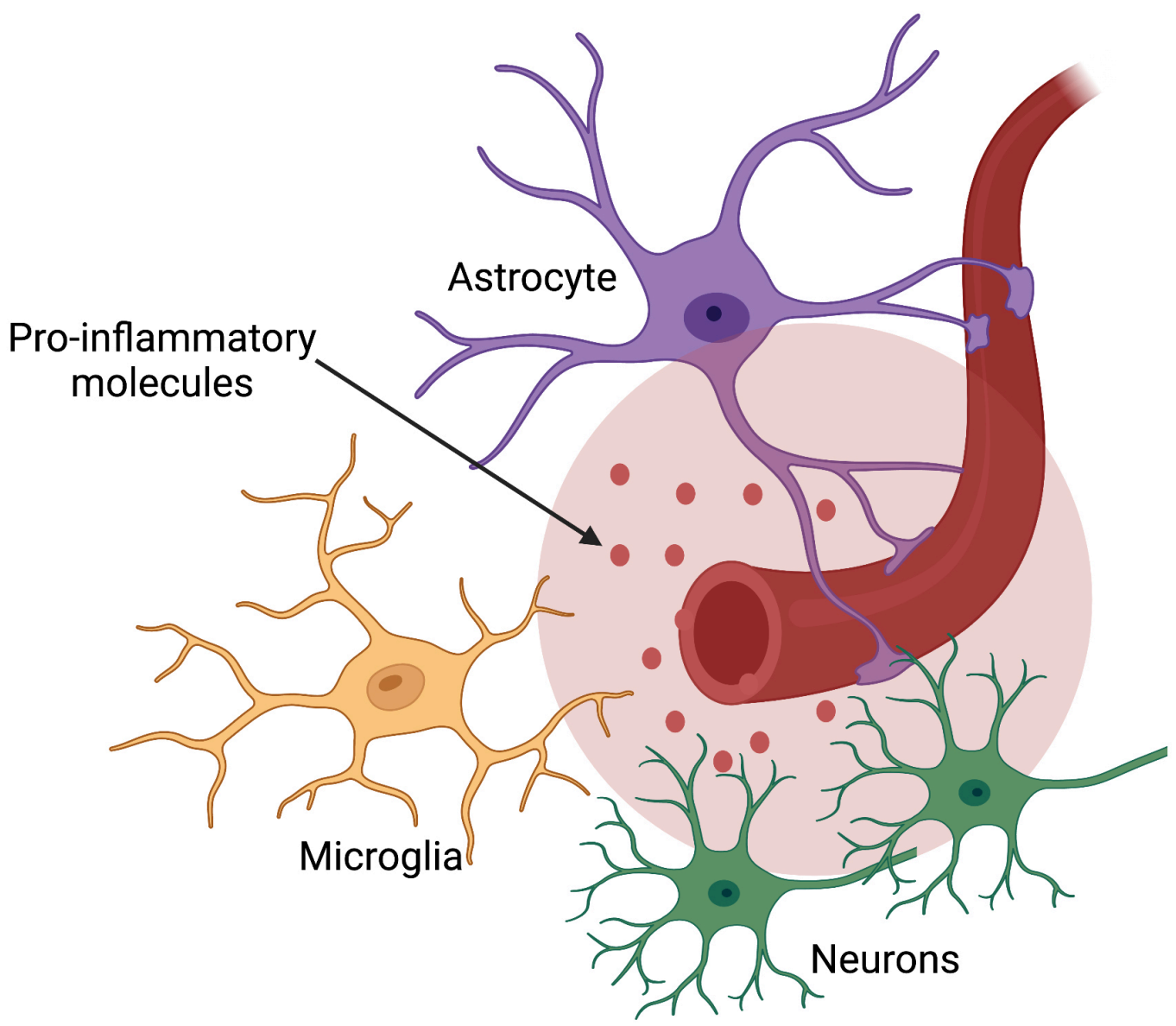

Fig. 3. A summary of key cells involved in the neurobiology of inflammation associated with PTH. The involvement of glial and immune cells, such as astrocytes and microglia, and secretion of pro-inflammatory molecules in post-traumatic headache after cervical damage can contribute to PTH formation by hyper-excitability and hyper-activity nociceptors.

face area from MRI scans of persistent PTH patients with migraine patients and controls, a study showed that structural differences exist in the brain if PTH patients and migraine, indicating potential unique neuropathophysiology [122]. Particularly, structural differences were observed in the right lateral orbitofrontal lobe, left caudal middle frontal lobe, left superior frontal lobe, left precuneus, and right supramarginal gyrus [122]. Brain measurements from these regions did not differ significantly between migraine and healthy controls [122]. Other studies supported these results by finding that TBI patients had a reduction in the cortical thickness in the frontotemporal region, which is particularly susceptible to TBI $[123,124]$, abnormal enlargement of lateral ventricles [125], and a decline in episodic memory and verbal fluency [125]. However, such differences were not found in mild TBI patients' cerebellum or subcortical regions compared to controls [124].

Changes in the frontal region of the brain have been found in patients with migraine, cluster headache and medication overdose headache [126-129], and frontal regions play a significant role in encoding, evaluation, and affective response in the pain and reward pathway [130, 131], suggesting a potential link between structural and functional changes to pain perception areas and PTH. For example, the precuneus, which was previously shown to be involved in migraine, cluster headache and medication overdose headache [126, 132$134]$, is associated with the default mode network and plays a pivotal role in determining the pain sensitivity and pain threshold [134-137]. In addition, the supramarginal gyrus is involved in migraines and medication overdose headaches $[138,139]$ and can play a role in the evaluation of pain $[140,141]$. While the exact etiology remains to be discovered, one can speculate that these regions are more susceptible to injury during TBI and can trigger PTH [122].

The plasticity of the brain can change in TBI patients with PTH. Imaging studies revealed significant correlations between years lived with headache with functional connectivity of different brain regions such as right primary somatosensory and left supramarginal gyrus [112], indicating a potential causal correlation. Similar functional connectivity, but in different brain regions, namely left middle cingulate with right pulvinar and right posterior insula with left hypothalamus, 
correlated with the frequency of PTH [112]. Therefore, it is plausible that despite overlaps in clinical symptoms, migraine and PTH can have unique neuropathophysiologies. Future large data sets with the help of artificial intelligence analysis [142] are required to establish the neurobiological changes associated with TBI.

Although there is less abundance of electroencephalography (EEG) data on PTH than neuroimaging, some studies dating back a few decades ago reported early abnormalities such as focal swelling, amplitude asymmetry, and absence of fast activity [143-145].

Discriminative pain pathways can also be affected in PTH (Fig. 4). Recent data on impaired descending modulation has been suggested as one of the underlying reasons for PTH [73]. Descending pain modulation system is responsible for connecting various cerebral sites and neuronal pathways to control pain [146]. A lack of balance between descending inhibitory and descending facilitatory systems can play a crucial role in chronic pain [146], and such imbalance can contribute to PTH [73]. While data on the role of descending pain modulation system in PTH is scarce, restoring the balance by pharmacological interventions can potentially offer a therapeutic option to PTH patients. Future advanced imaging studies are required to have a better understanding of descending pain modulation system and $\mathrm{PTH}$.

To assess the sensory profile of PTH patients by using systematic quantitative somatosensory testing, Defrin et al. [95] showed that generalized impairment of the spinothalamic system following TBI could result in a higher threshold for thermal sensation. This effect was specific as the threshold of light touch, and graphesthesia was not different in PTH patients, indicating an intact dorsal column system transmitting tactile sensations [147]. Furthermore, PTH patients reported pain from normally innocuous stimuli (allodynia) on the head [95].

Abnormalities in functional connectivity following TBI can result in cognitive deficits and post-concussive symptoms such as PTH [148]. A reduced regional cerebral blood flow was observed in patients with PTH [102]. Single-photon emission computed tomography (SPECT) studies corroborated these findings by demonstrating that cerebral blood flow can differ in TBI patients within days to years after the injury [149-151]. In comparison, arterial spine labeling (ASL) studies have produced contradicting results on cerebral perfusion following head trauma. A study reported an increased cerebral blood flow in the left dorsal anterior cingulate cortex and left insula of 15 teenage athletes after sports-related concussion compared to 15 matched controls [152]. In contrast, cerebral blood flow was decreased in bilateral frontotemporal regions of 14 chronic sports-related and recreational pediatric patients with mild TBI compared to 15 controls [153].

Similarly, another study on twelve children aged 11-15 years with sports-related concussions found decreased cerebral blood flow in mild TBI patients. However, $64 \%$ of par- ticipants showed improvements towards controls' cerebral blood flow value at $>30$ days after the injury [154]. Cerebral blood flow was also increased in pediatric TBI patients with post-traumatic symptoms, but no increase was observed in asymptomatic patients [152, 155]. Contradictory to these findings, while pediatric patients showed normal neurophysiological scores seven months post-concussion, a bilateral decrease in cerebral blood flow was observed in frontotemporal regions [153]. It is plausible to conclude that TBI can cause changes in cerebral blood flow, which are more significant in symptomatic patients [77]. Future studies are required to assess the association between cerebral blood flow and PTH and the recovery time.

\subsection{Treatment of post-traumatic headache}

Headache interrupts and demands attention. Despite the high prevalence of PTH, there is no global consensus on PTH treatment, and a variety of approaches exist regarding the appropriate treatment. To provide a better framework for the treatment of $\mathrm{PTH}$, many physicians rely on the management of primary headache to address $\mathrm{PTH}$, which, as mentioned previously, is a secondary headache $[36,106,156]$; this can result in undesired and poor response to treatments [157].

There is a lack of evidence-based studies on pharmacological interventions of persistent PTH [158]. To the best of my knowledge, no Food and Drug Administration (FDA)approved drug exists for PTH, and no randomized controlled clinical trial has assessed the effectiveness of treatments for PTH. PTH patients, therefore, experience unnecessary and irrelevant treatments [158]. Effective pharmacological intervention for PTH should address both the intensity and frequency of headache attacks [39]. Comorbidities, side effects and efficacy for treating primary headache, which resembles $\mathrm{PTH}$, can affect the choice of drug used [159].

Pharmacological intervention of the acute phase of PTH consists of analgesic and non-analgesic treatments. Analgesic drugs such as acetaminophen [27], ketorolac [160], nonsteroid anti-inflammatory drugs [27], and a mixture of drugs (Midrin, Cafergot, Excedrin) [27] can be used for the acute treatment of PTH. A study showed that more than $70 \%$ of individuals with headaches used acetaminophen or non-steroid anti-inflammatory medications to manage their symptoms [42]. Other specific analgesic drugs for PTH include lidocaine [161], opioids and triptans [27]. Antiemetic drugs prescribed to treat nausea and vomiting associated with PTH are prochlorperazine [160], ondansetron [160], and metoclopramide $[160,162]$. Other drugs used for the acute treatment of PTH include diphenhydramine [162], triamcinolone and methylprednisolone acetate [163].

Mild TBI patients with PTH might rely on self-treatments by using over-the-counter medications to relieve their pains and symptoms, even though such medications are not effective for all patients [42]. Over-the-counter prescriptions such as paracetamol (acetaminophen), ibuprofen, aspirin, and naproxen are used to treat tension-type headaches [39]. Self-medication can result in medication overdose, and pa- 


\section{Discriminative Pain Pathways}

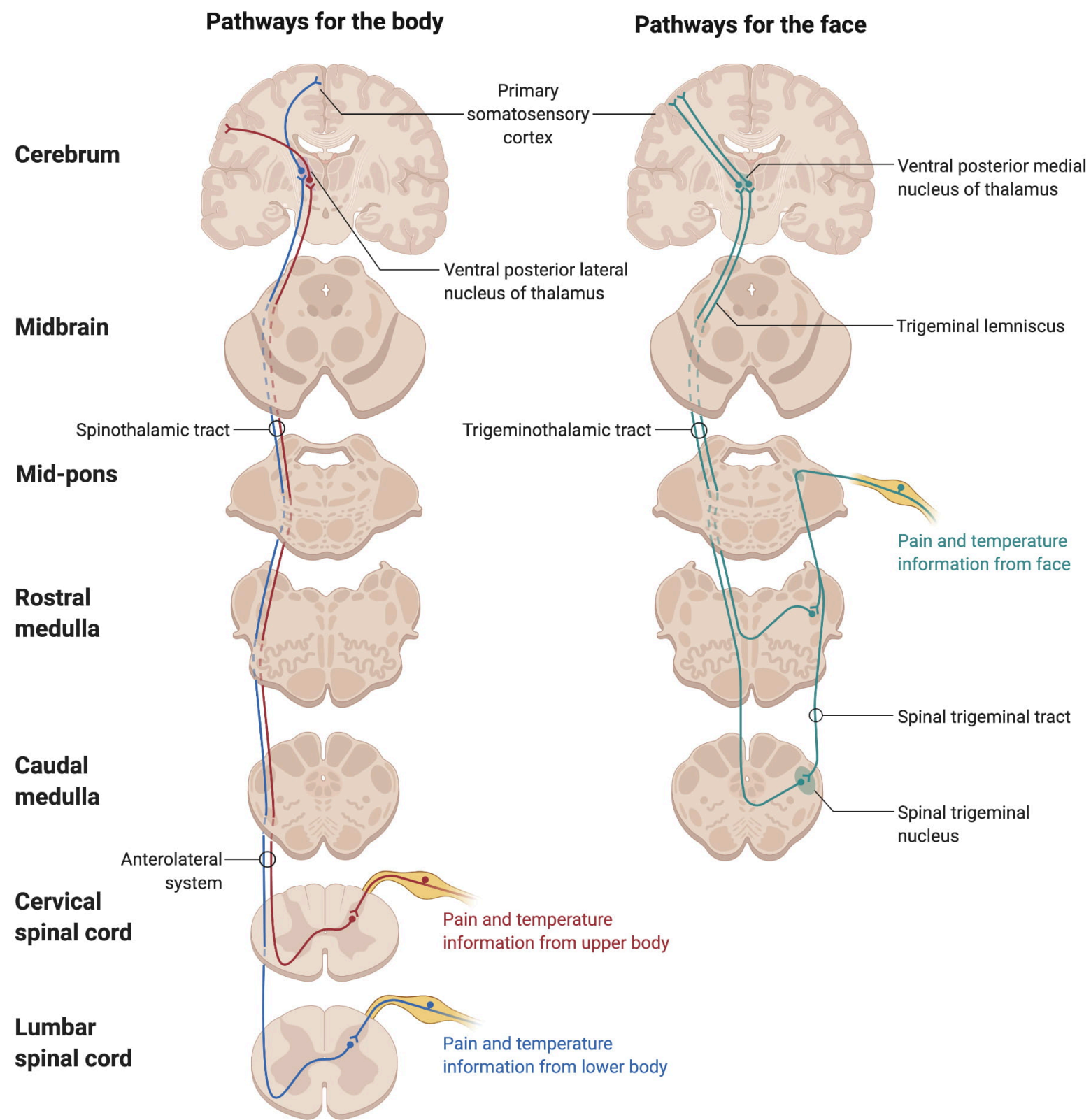

Fig. 4. An overview of the discriminative pain pathways in the body and face. The pain pathways can be affected in PTH. Nociceptors, as free nerve endings, act as afferent nerve fibers with their cell bodies located in terminal ganglion or dorsal root ganglia, terminating in the dorsal horn of the spinal cord. While all pain fibers terminate in the dorsal horn, they adopt different routes to this location, with most entering the dorsal horn via the ventrolateral bundle of the dorsal root. Second-order neurons ascend to higher brain centers in the anterolateral section of the spinal cord via spinothalamic and spinoreticular tracts. The thalamus processes somatosensory information. Descending pathways of pain play roles in modulating pain.

tients with persistent headaches after trauma can develop headaches associated with medication overdose [168], which can negatively impact the quality of their lives [164]. Excessive usage of analgesic medications after a concussion can also contribute to PTH development [165]. Medication overdose headache can resemble migraine, tension-type headache, or the underlying headache $[165,166]$. $19 \%-42 \%$ of PTH pa- tients can face excessive analgesic use, and the majority of them experience improvements in their symptoms after medication withdrawal $[167,168]$.

Effective treatment of PTH requires appropriate classification. Most PTHs can be classified using primary headache criteria, and the majority of PTH cases are classified as migraine and probable migraine using such criteria [106]. 
Intravenous migraine therapy using prochlorperazine, ondansetron, and metoclopramide reduced the PTH scores reported by children 8 to 21 years old 14 days after mild TBI [160]. Treatment of acute PTH in children can be relatively successful as $38 \%-55 \%$ of children with PTH have symptoms resembling acute migraine headaches [106], effectively treated by ketorolac, metoclopramide and prochlorperazine [169-172]. A small study of 21 patients with PTH showed that intravenous metoclopramide and diphenhydramine were effective treatments for acute PTH [162].

Some reports of successful PTH have been made using various drugs such as amitriptyline [173], botulinum toxin [174], intravenous chlorpromazine [175], intravenous dihydroergotamine with metoclopramide [176], divalproex sodium [177], intraoral topical ketoprofen [178], and subcutaneous sumatriptan [179]. Like chronic tension-type headaches, PTH patients can be treated with prophylactic medications such as amitriptyline [168] or its metabolite, nortriptyline, which has lower anticholinergic side effects [180]. Medications such as triptan class drugs as selective serotonin receptor inhibitors can treat PTH [27].

Nerve blockage is another approach for the treatment of acute PTH. Dubrovsky et al. [181] showed that peripheral nerve blockade of the scalp immediately relieved symptoms of young PTH patients below 18. Occipital nerve blockage using lidocaine and methylprednisolone acetate, which is used to treat occipital neuralgia, can also alleviate acute PTH symptoms [163]. Cognitive-behavioral therapy can supplement pharmacological interventions for PTH to achieve a better patient outcome [182].

Recent structural and functional neuroimaging data have revealed that different networks other than migraine exist in persistent PTH [183]. Furthermore, calcitonin generelated peptide gene expression level is not elevated in persistent PTH, but monoclonal antibodies against calcitonin generelated peptide gene can be effective [183]. Future results from trials assessing the efficacy of such medications can provide novel treatments for PTH.

\subsection{Psychological aspect of headache after traumatic brain injury}

Although Lishman originally proposed that neurobiological factors contribute to the formation of the post-concussive syndrome and psychological factors account for the maintenance of symptoms in the chronic phase [12], we now understand that both neurobiological and psychological factors play pivotal roles in post-concussive syndrome from its onset [13]. Patients suffering from PTH can have psychological symptoms such as anxiety, depression, insomnia [80]. Anxiety and depression are major causes of disability [184] and can significantly hinder individuals from reaching their full potential [185]. Experiencing mTBI can be related to behavioral changes such as attention-deficit/hyperactivity disorder, substance abuse, and mood disorder [186]. A study showed that patients with persistent PTH had higher levels of depression and anxiety compared to patients with migraine and healthy controls [122].
Other psychological conditions such as post-traumatic stress disorder can be associated with PTH or exacerbate its symptoms [186-189]. Another complication associated with TBI is that some of the clinical symptoms, such as a cognitive decline in late adulthood, manifest many decades after the apparent recovery from the injury, making it challenging to establish a connection between TBI and symptoms [125]. Furthermore, patients with mild TBI tend to be hypervigilant, meaning they are excessively concerned about injuries to their brains and associated physical symptoms such as headaches [92, 111, 190]. Hypervigilance can potentially change brain networks responsible for the perception and modulation of pain [5]. Therefore, excessive attention to pain can explain the lower threshold and higher perception of headaches and pain in TBI patients [191, 192].

Therefore, considering their psychological well-being, a holistic approach to PTH patient treatment is essential to achieve better outcomes. Psychological treatments for TBI patients with headaches should be an integral part of their treatment regimen.

\subsection{Challenges associated with studying post-traumatic headache}

There are multiple challenges associated with studying PTH in TBI patients. One major limitation is that many TBI patients can have comorbidities which can act as confounding factors to affect the phenotypes observed from radiological and neurophysiological data [122]. As previously mentioned, some PTH patients can suffer from stress, anxiety, depression and PTSD and use medications for psychological problems [193, 194]. Therefore, it remains challenging to disentangle whether some functional and structural changes seen in PTH patients' brains are consequences of medications or not. Future robust studies are required to address this issue.

As previously mentioned, some TBI patients with PTH can have pre-existing headaches, which can be exacerbated by the injury $[16,60]$. Therefore, another caveat of some PTH studies is the inclusion of participants with pre-existing headaches or not evaluating whether participants had preexisting headaches. Patients with pre-existing headaches might be more susceptible to developing a headache after TBI [16]. Furthermore, TBI patients can use medications before the initiation of studies that can affect the data.

Another major limitation is the lack of sufficient evidence to disentangle the effect of trauma during TBI from PTH on the brain. It is not clear whether some of the structural and functional changes found in studies were due to trauma on the brain or simply because of the headache. Future studies where TBI patients without headaches are compared to TBI patients with PTH can answer these gaps in our knowledge.

Combining these limitations and caveats means that future studies are required to better address questions regarding PTH.

\section{Conclusions}

In conclusion, as PTH is a multi-faceted condition, its treatment should be multi-faceted and multi-disciplinary too. 
A holistic and personalized approach to integrating pharmacological and non-pharmacological interventions such as lifestyle modifications and stress management can effectively treat persistent PTH [130]. In addition to their headache, TBI patients can suffer from other symptoms, including anxiety, depression, PTSD, which requires medications [193, 194]. Future involvement of artificial intelligence in clinical studies can reduce the subjectivity of clinical decision-making and patient care [142]. One of the main implications is that psychiatric conditions should be considered in PTH management to tailor the treatment to patients [49]. Psychiatric disorders can be neglected in managing headaches in TBI patients; however, long-term management of PTH patients needs to consider a biopsychosocial model for patient treatment [195]. Further research is required to understand the neurobiological and neuropathological mechanisms contributing to secondary headaches following TBI and pave the way for more effective, patient-centered treatments.

\section{Abbreviations}

CT, computerized tomography; ICHD, international classification of headache disorders; MRI, magnetic resonance imaging; PTH, post-traumatic headache; PTSD, posttraumatic stress disorder; TBI, traumatic brain injury.

\section{Author contributions}

MM conceptualized, prepared, drafted, and edited the paper.

\section{Ethics approval and consent to participate Not applicable.}

\section{Acknowledgment}

The author would like to thank Biorender for the figures.

\section{Funding}

This research received no external funding.

\section{Conflict of interest}

The author declares no conflict of interest.

\section{References}

[1] Defrin R, Riabinin M, Feingold Y, Schreiber S, Pick CG. Deficient Pain Modulatory Systems in Patients with Mild Traumatic Brain and Chronic Post-Traumatic Headache: Implications for its Mechanism. Journal of Neurotrauma. 2015; 32: 28-37.

[2] Dewan MC, Rattani A, Gupta S, Baticulon RE, Hung Y, Punchak $\mathrm{M}$, et al. Estimating the global incidence of traumatic brain injury. Journal of Neurosurgery. 2018; 1: 1-18.

[3] Zaloshnja E, Miller T, Langlois JA, Selassie AW. Prevalence of Long-Term Disability from Traumatic Brain Injury in the Civilian Population of the United States, 2005. The Journal of Head Trauma Rehabilitation. 2008; 23: 394-400.

[4] Cifu D, Hurley R, Peterson M, Cornis-Pop M, Rikli PA, Ruff RL, et al. VA/DoD Clinical Practice Guideline for Management of Concussion/Mild Traumatic Brain Injury. Journal of Rehabilitation Research and Development. 2009; 46: CP1-C68.

[5] Niu X, Bai L, Sun Y, Wang S, Cao J, Sun C, et al. Disruption of periaqueductal grey-default mode network functional connectiv- ity predicts persistent post-traumatic headache in mild traumatic brain injury. Journal of Neurology Neurosurgery and Psychiatry. 2019; 90: 326-332.

[6] Cassidy JD, Carroll LJ, Peloso PM, Borg J, von Holst H, Holm L, et al. Incidence, risk factors and prevention of mild traumatic brain injury: results of the WHO Collaborating Centre Task Force on Mild Traumatic Brain Injury. Journal of Rehabilitation Medicine. 2004; 43: 28-60.

[7] Blennow K, Brody DL, Kochanek PM, Levin H, McKee A, Ribbers GM, et al. Traumatic brain injuries. Nature Reviews Disease Primers. 2016; 2: 1-19.

[8] Mckee AC, Daneshvar DH. The neuropathology of traumatic brain injury. Handbook of Clinical Neurology. 2015; 127: 45-66.

[9] Krainin BM, Forsten RD, Kotwal RS, Lutz RH, Guskiewicz KM. Mild traumatic brain injury literature review and proposed changes to classification. Journal of Special Operations Medicine. 2011; 11: 38-47.

[10] Faul M, Xu L, Wald MM, Coronado VG. Traumatic brain injury in the United States: emergency department visits, hospitalizations and deaths 2002-2006. Centers for Disease Control and Prevention. 2010.

[11] McCrory P, Meeuwisse WH, Aubry M, Cantu B, Dvořák J, Echemendia RJ, et al. Consensus statement on concussion in sport: the 4th International Conference on Concussion in Sport held in Zurich, November 2012. British Journal of Sports Medicine. 2013; 47: 250-258.

[12] Lishman WA. Physiogenesis and Psychogenesis in the 'PostConcussional Syndrome'. The British Journal of Psychiatry. 1988; 153: 460-469.

[13] Silverberg ND, Iverson GL. Etiology of the post-concussion syndrome: Physiogenesis and psychogenesis revisited. NeuroRehabilitation. 2011; 29: 317-329.

[14] Bieniek KF, Ross OA, Cormier KA, Walton RL, Soto-Ortolaza A, Johnston AE, et al. Chronic traumatic encephalopathy pathology in a neurodegenerative disorders brain bank. Acta Neuropathologica. 2015; 130: 877-889.

[15] Gfeller JD, Chibnall JT, Duckro PN. Postconcussion Symptoms and Cognitive Functioning in Posttraumatic Headache Patients. Headache. 1994; 34: 503-507.

[16] Lieba-Samal D, Platzer P, Seidel S, Klaschterka P, Knopf A, Wöber C. Characteristics of acute posttraumatic headache following mild head injury. Cephalalgia. 2011; 31: 1618-1626.

[17] Packard RC, Weaver R, Ham LP. Cognitive Symptoms in Patients with Posttraumatic Headache. Headache. 1993; 33: 365-368.

[18] Head J. Definition of mild traumatic brain injury. Journal of Head Trauma Rehabilitation. 1993; 8: 86-87.

[19] West TA, Marion DW. Current Recommendations for the Diagnosis and Treatment of Concussion in Sport: A Comparison of Three New Guidelines. Journal of Neurotrauma. 2014; 31: 159168.

[20] McInnes K, Friesen CL, MacKenzie DE, Westwood DA, Boe SG Mild Traumatic Brain Injury (mTBI) and chronic cognitive impairment: A scoping review. PLoS ONE. 2017; 12: e0174847.

[21] Barman A, Chatterjee A, Bhide R. Cognitive Impairment and Rehabilitation Strategies After Traumatic Brain Injury. Indian Journal of Psychological Medicine. 2016; 38: 172-181.

[22] Schwarzbold M, Diaz A, Martins ET, Rufino A, Amante LN, Thais $\mathrm{ME}$, et al. Psychiatric disorders and traumatic brain injury. Neuropsychiatric Disease and Treatment. 2008; 4: 797-816.

[23] Fleminger S. Long-term psychiatric disorders after traumatic brain injury. European Journal of Anaesthesiology. 2008; 42: 123 130.

[24] Meares S, Shores EA, Taylor AJ, Batchelor J, Bryant RA, Baguley $\mathrm{IJ}$, et al. The prospective course of postconcussion syndrome: The role of mild traumatic brain injury. Neuropsychology. 2011; 25: 454-465.

[25] Ponsford J, Cameron P, Fitzgerald M, Grant M, Mikocka-Walus A. Long-Term Outcomes after Uncomplicated Mild Traumatic 
Brain Injury: A Comparison with Trauma Controls. Journal of Neurotrauma. 2011; 28: 937-946.

[26] Kjeldgaard D, Forchhammer H, Teasdale T, Jensen RH. Chronic post-traumatic headache after mild head injury: A descriptive study. Cephalalgia. 2014; 34: 191-200.

[27] Erickson JC. Treatment Outcomes of Chronic Post-Traumatic Headaches After Mild Head Trauma in US Soldiers: An Observational Study. Headache. 2011; 51: 932-944.

[28] Kontos AP, Elbin RJ, Lau B, Simensky S, Freund B, French J, et al. Posttraumatic Migraine as a Predictor of Recovery and Cognitive Impairment After Sport-Related Concussion. The American Journal of Sports Medicine. 2013; 41: 1497-1504.

[29] Defrin R. Chronic post-traumatic headache: clinical findings and possible mechanisms. Journal of Manual \& Manipulative Therapy. 2014; 22: 36-43.

[30] Faux S, Sheedy J. A Prospective Controlled Study in the Prevalence of Posttraumatic Headache Following Mild Traumatic Brain Injury. Pain Medicine. 2008; 9: 1001-1011.

[31] Stacey A, Lucas S, Dikmen S, Temkin N, Bell KR, Brown A, et al. Natural History of Headache Five Years after Traumatic Brain Injury. Journal of Neurotrauma. 2016; 34: 1558-1564.

[32] Uomoto J, Esselman P. Traumatic brain injury and chronic pain: differential types and rates by head injury severity. Archives of Physical Medicine and Rehabilitation. 1993; 74: 61-64.

[33] Lahz S, Bryant RA. Incidence of chronic pain following traumatic brain injury. Archives of Physical Medicine and Rehabilitation. 1996; 77: 889-891.

[34] Dikmen S, Machamer J, Fann JR, Temkin NR. Rates of symptom reporting following traumatic brain injury. Journal of the International Neuropsychological Society. 2010; 16: 401-411.

[35] Lucas S, Hoffman JM, Bell KR, Dikmen S. A prospective study of prevalence and characterization of headache following mild traumatic brain injury. Cephalalgia. 2014; 34: 93-102.

[36] Lew HL, Lin P-H, Fuh J-L, Wang S-J, Clark DJ, Walker WC. Characteristics and Treatment of Headache After Traumatic Brain Injury: A Focused Review. American Journal of Physical Medicine \& Rehabilitation. 2006; 85: 619-627.

[37] Stovner LJ, Schrader H, Mickevičiene D, Surkiene D, Sand T. Headache after concussion. European Journal of Neurology. 2009; 16: $112-120$.

[38] Gladstone J. From Psychoneurosis to ICHD-2: An Overview of the State of the Art in Post-Traumatic Headache. Headache. 2009; 49: 1097-1111.

[39] Labastida-Ramírez A, Benemei S, Albanese M, D’Amico A, Grillo G, Grosu O, et al. Persistent post-traumatic headache: a migrainous loop or not? The clinical evidence. The Journal of Headache and Pain. 2020; 21: 55.

[40] Wang Y, Chan RCK, Deng Y. Examination of postconcussion-like symptoms in healthy university students: Relationships to subjective and objective neuropsychological function performance. Archives of Clinical Neuropsychology. 2006; 21: 339-347.

[41] Zakzanis KK, Yeung E. Base Rates of Post-concussive Symptoms in a Nonconcussed Multicultural Sample. Archives of Clinical Neuropsychology. 2011; 26: 461-465.

[42] DiTommaso C, Hoffman JM, Lucas S, Dikmen S, Temkin N, Bell KR. Medication Usage Patterns for Headache Treatment after Mild Traumatic Brain Injury. Headache. 2014; 54: 511-519.

[43] Lantéri-Minet M, Duru G, Mudge M, Cottrell S. Quality of life impairment, disability and economic burden associated with chronic daily headache, focusing on chronic migraine with or without medication overuse: a systematic review. Cephalalgia. 2011; 31: 837-850.

[44] Seifert TD, Evans RW. Posttraumatic Headache: A Review. Current Pain and Headache Reports. 2010; 14: 292-298.

[45] Lucas S. Characterization and Management of Headache after Mild Traumatic Brain Injury. Brain Neurotrauma. 2015.

[46] Pompili M, Serafini G, Di Cosimo D, Dominici G, Innamorati M, Lester D, et al. Psychiatric comorbidity and suicide risk in patients with chronic migraine. Neuropsychiatric Disease and Treatment. 2010; 6: 81-91.

[47] Serafini G, Pompili M, Innamorati M, Gentile G, Borro M, Lamis $\mathrm{DA}$, et al. Gene variants with suicidal risk in a sample of subjects with chronic migraine and affective temperamental dysregulation. European Review for Medical and Pharmacological Sciences. 2012; 16: 1389-1398.

[48] Caponnetto V, Deodato M, Robotti M, Koutsokera M, Pozzilli V, Galati C, et al. Comorbidities of primary headache disorders: a literature review with meta-analysis. The Journal of Headache and Pain. 2021; 22: 71.

[49] Dresler T, Caratozzolo S, Guldolf K, Huhn JI, Loiacono C, Niiberg-Pikksööt T, et al. Understanding the nature of psychiatric comorbidity in migraine: a systematic review focused on interactions and treatment implications. The Journal of Headache and Pain. 2019; 20: 51.

[50] Guglielmetti M, Serafini G, Amore M, Martelletti P. The Relation between Persistent Post-Traumatic Headache and PTSD: Similarities and Possible Differences. International Journal of Environmental Research and Public Health. 2020; 17: 4024.

[51] Benemei S, Labastida-Ramírez A, Abramova E, Brunelli N, Caronna E, Diana P, et al. Persistent post-traumatic headache: a migrainous loop or not? the preclinical evidence. The Journal of Headache and Pain. 2020; 21: 90.

[52] Habibzadeh P, Mofatteh M, Silawi M, Ghavami S, Faghihi MA. Molecular diagnostic assays for COVID-19: an overview. Critical Reviews in Clinical Laboratory Sciences. 2021; 58: 385-398.

[53] Habibzadeh P, Silawi M, Dastsooz H, Bahramjahan S, Ezzatzadegan Jahromi S, Ostovan VR, et al. Clinical and molecular characterization of a patient with mitochondrial Neurogastrointestinal Encephalomyopathy. BMC Gastroenterology. 2020; 20: 142.

[54] Arnold M. Headache Classification Committee of the International Headache Society (IHS) the International Classification of Headache Disorders, 3rd edition. Cephalalgia. 2018; 38: 1-211.

[55] Nampiaparampil DE. Prevalence of Chronic Pain after Traumatic Brain Injury: a systematic review. The Journal of the American Medical Association. 2008; 300: 711-719.

[56] Voormolen DC, Cnossen MC, Polinder S, Gravesteijn BY, Von Steinbuechel N, Real RGL, et al. Prevalence of post-concussionlike symptoms in the general population in Italy, the Netherlands and the United Kingdom. Brain Injury. 2019; 33: 1078-1086.

[57] Jensen O, Thulstrup A. Gender differences of post-traumatic headache and other post-commotio symptoms. A follow-up study after a period of 9-12 months. Ugeskrift for Laeger. 2001; 163: 5029-5033.

[58] Nordhaug LH, Linde M, Follestad T, Skandsen ØN, Bjarkø VV, Skandsen T, et al. Change in Headache Suffering and Predictors of Headache after Mild Traumatic Brain Injury: A Population-Based, Controlled, Longitudinal Study with Twelve-Month Follow-up. Journal of Neurotrauma. 2019; 36: 3244-3252.

[59] Yilmaz T, Roks G, de Koning M, Scheenen M, van der Horn $\mathrm{H}$, Plas $\mathrm{G}$, et al. Risk factors and outcomes associated with posttraumatic headache after mild traumatic brain injury. Emergency Medicine Journal. 2017; 34: 800-805.

[60] Chan TLH, Woldeamanuel YW. Exploring naturally occurring clinical subgroups of post-traumatic headache. The Journal of Headache and Pain. 2020; 21: 12.

[61] Wojcik SM. Predicting mild traumatic brain injury patients at risk of persistent symptoms in the Emergency Department. Brain Injury. 2014; 28: 422-430.

[62] Nordhaug LH, Vik A, Hagen K, Stovner LJ, Pedersen T, Gravdahl GB, et al. Headaches in patients with previous head injuries: a population-based historical cohort study (HUNT). Cephalalgia. 2016; 36: 1009-1019.

[63] Wäljas M, Iverson GL, Lange RT, Hakulinen U, Dastidar P, Huhtala $\mathrm{H}$, et al. A Prospective Biopsychosocial Study of the Persistent Post-Concussion Symptoms following Mild Traumatic Brain Injury. Journal of Neurotrauma. 2015; 32: 534-547. 
[64] Hong C, Shim YS, Sim SY, Joo J, Kwon MA, Kim YB, et al. Post-traumatic headache in patients with minimal traumatic intracranial hemorrhage after traumatic brain injury: a retrospective matched case-control study. The Journal of Headache and Pain. 2017; 18: 64.

[65] Walker WC, Marwitz JH, Wilk AR, Ketchum JM, Hoffman JM, Brown AW, et al. Prediction of headache severity (density and functional impact) after traumatic brain injury: a longitudinal multicenter study. Cephalalgia. 2013; 33: 998-1008.

[66] Hoffman JM, Lucas S, Dikmen S, Braden CA, Brown AW, Brunner R, et al. Natural History of Headache after Traumatic Brain Injury. Journal of Neurotrauma. 2011; 28: 1719-1725.

[67] Jensen OK, Nielsen FF. The Influence of Sex and Pre-Traumatic Headache on the Incidence and Severity of Headache after Head Injury. Cephalalgia. 1990; 10: 285-293.

[68] Nestvold K, Lundar T, Mowinckel P, Stavem K. Predictors of headache 22 years after hospitalization for head injury. Acta Neurologica Scandinavica. 2005; 112: 13-18.

[69] Lange RT, Iverson GL, Rose A. Depression Strongly Influences Postconcussion Symptom Reporting Following Mild Traumatic Brain Injury. Journal of Head Trauma Rehabilitation. 2011; 26: 127-137.

[70] Jouzdani SR, Ebrahimi A, Rezaee M, Shishegar M, Tavallaii A, Kaka G. Characteristics of posttraumatic headache following mild traumatic brain injury in military personnel in Iran. Environmental Health and Preventive Medicine. 2014; 19: 422-428.

[71] Lucas S. Headache Management in Concussion and Mild Traumatic Brain Injury. Physical Medicine and Rehabilitation. 2011; 3: S406-S412.

[72] Olesen J. Preface to the second Edition. Cephalalgia. 2004; 24: 910.

[73] Ashina H, Porreca F, Anderson T, Amin FM, Ashina M, Schytz HW, et al. Post-traumatic headache: epidemiology and pathophysiological insights. Nature Reviews Neurology. 2019; 15: 607-617.

[74] Theeler BJ, Flynn FG, Erickson JC. Headaches after Concussion in us Soldiers Returning from Iraq or Afghanistan. Headache. 2010; 50: 1262-1272.

[75] Theeler BJ, Flynn FG, Erickson JC. Chronic Daily Headache in U.S. Soldiers After Concussion. Headache. 2012; 52: 732-738.

[76] Stovner LJ, Nichols E, Steiner TJ, Abd-Allah F, Abdelalim A, AlRaddadi RM, et al. Global, regional, and national burden of migraine and tension-type headache, 1990-2016: a systematic analysis for the Global Burden of Disease Study 2016. The Lancet Neurology. 2018; 17: 954-976.

[77] Ashina H, Iljazi A, Al-Khazali HM, Ashina S, Jensen RH, Amin FM, et al. Persistent post-traumatic headache attributed to mild traumatic brain injury: Deep phenotyping and treatment patterns. Cephalalgia. 2020; 40: 554-564.

[78] Headache Classification Committee of the International Headache Society (IHS). The International Classification of Headache Disorders, 3rd edition (beta version). Cephalalgia. 2013; 33: 629-808.

[79] Jensen RH. Tension-Type Headache - The Normal and Most Prevalent Headache. Headache. 2018; 58: 339-345.

[80] Minen MT, Boubour A, Walia H, Barr W. Post-Concussive Syndrome: A Focus on Post-Traumatic Headache and Related Cognitive, Psychiatric, and Sleep Issues. Current Neurology and Neuroscience Reports. 2016; 16: 100.

[81] Levin HS, Diaz-Arrastia RR. Diagnosis, prognosis, and clinical management of mild traumatic brain injury. The Lancet Neurology. 2015 ; 14: 506-517.

[82] Howard L, Dumkrieger G, Chong CD, Ross K, Berisha V, Schwedt TJ. Symptoms of Autonomic Dysfunction among those with Persistent Posttraumatic Headache Attributed to Mild Traumatic Brain Injury: A Comparison to Migraine and Healthy Controls. Headache. 2018; 58: 1397-1407.

[83] Gee JR, Ishaq Y, Vijayan N. Postcraniotomy Headache. Headache. 2003; 43: 276-278.

[84] Ivanhoe CB, Hartman ET. Clinical Caveats on Medical Assess- ment and Treatment of Pain after TBI. The Journal of Head Trauma Rehabilitation. 2004; 19: 29-39.

[85] Sahbaie P, Irvine K, Liang D, Shi X, Clark JD. Mild Traumatic Brain Injury Causes Nociceptive Sensitization through Spinal Chemokine Upregulation. Scientific Reports. 2019; 9: 19500.

[86] Chong CD, Berisha V, Ross K, Kahn M, Dumkrieger G, Schwedt TJ. Distinguishing persistent post-traumatic headache from migraine: Classification based on clinical symptoms and brain structural MRI data. Cephalalgia. 2021; 41: 943-955.

[87] Mayer CL, Huber BR, Peskind E. Traumatic brain injury, neuroinflammation, and post-traumatic headaches. Headache. 2013; 53: 1523-1530.

[88] Shohami E, Ginis I, Hallenbeck JM. Dual role of tumor necrosis factor alpha in brain injury. Cytokine \& Growth Factor Reviews. 1999; 10: 119-130.

[89] Baratz R, Tweedie D, Rubovitch V, Luo W, Yoon JS, Hoffer BJ, et al. Tumor necrosis factor- $\alpha$ synthesis inhibitor, 3,6dithiothalidomide, reverses behavioral impairments induced by minimal traumatic brain injury in mice. Journal of neurochemistry. 2011; 118: 1032-1042.

[90] Elliott MB, Oshinsky ML, Amenta PS, Awe OO, Jallo JI. Nociceptive neuropeptide increases and periorbital allodynia in a model of traumatic brain injury. Headache. 2012; 52: 966-984.

[91] Perez-Polo JR, Rea HC, Johnson KM, Parsley MA, Unabia GC, Xu $\mathrm{G}$, et al. Inflammatory Consequences in a Rodent Model of Mild Traumatic Brain Injury. Journal of Neurotrauma. 2013; 30: 727740.

[92] Woolf CJ. Evidence for a central component of post-injury pain hypersensitivity. Nature. 1983; 306: 686-688.

[93] McMahon SB, Lewin GR, Wall PD. Central hyperexcitability triggered by noxious inputs. Current Opinion in Neurobiology. 1993; 3: 602-610.

[94] Bendtsen L. Central Sensitization in Tension-Type HeadachePossible Pathophysiological Mechanisms. Cephalalgia. 2000; 20: 486-508.

[95] Defrin R, Tsedek I, Lugasi I, Moriles I, Urca G. The interactions between spatial summation and DNIC: Effect of the distance between two painful stimuli and attentional factors on pain perception. Pain. 2010; 151: 489-495.

[96] Devor M, Govrin-Lippmann R, Rappaport ZH. Mechanism of trigeminal neuralgia: an ultrastructural analysis of trigeminal root specimens obtained during microvascular decompression surgery. Journal of Neurosurgery. 2002; 96: 532-543.

[97] Luo D, Zhang T, Zuo CX, Zuo ZF, Li H, Wu SX, et al. An Animal Model for Trigeminal Neuralgia by Compression of the Trigeminal Nerve Root. Pain physician. 2012; 15: 187-196.

[98] Liang H, Hippenmeyer S, Ghashghaei HT. A Nestin-cre transgenic mouse is insufficient for recombination in early embryonic neural progenitors. Biology Open. 2012; 1: 1200-1203.

[99] Jang SH, Seo YS. Headache due to spinothalamic tract injury in patients with mild traumatic brain injury: Two case reports. Medicine. 2019; 98: e14306.

[100] Moen KG, Skandsen T, Folvik M, Brezova V, Kvistad KA, Rydland J, et al. A longitudinal MRI study of traumatic axonal injury in patients with moderate and severe traumatic brain injury. Journal of Neurology Neurosurgery and Psychiatry. 2012; 83: 1193-1200.

[101] Gilkey SJ, Ramadan NM, Aurora TK, Welch KMA. Cerebral Blood Flow in Chronic Posttraumatic Headache. Headache. 1997; 37: 583-587.

[102] Yi JH, Hazell AS. Excitotoxic mechanisms and the role of astrocytic glutamate transporters in traumatic brain injury. Neurochemistry International. 2006; 48: 394-403.

[103] Larsson LI, Edvinsson L, Fahrenkrug J, Håkanson R, Owman C. Immunohistochemical localization of a vasodilatory polypeptide (VIP) in cerebrovascular nerves. Brain Research. 1976; 113: 400404.

[104] Lauritzen M. Pathophysiology of the migraine aura: The spreading depression theory. Brain. 1994; 117: 199-210. 
[105] Taylor AR, Bell TK. Slowing of Cerebral Circulation after Concussional Head Injury: A Controlled Trial. The Lancet. 1966; 288: 178-180.

[106] Lucas S, Hoffman JM, Bell KR, Walker W, Dikmen S. Characterization of headache after traumatic brain injury. Cephalalgia. 2012; 32: 600-606.

[107] Alhilali LM, Delic J, Fakhran S. Differences in Callosal and Forniceal Diffusion between Patients with and without Postconcussive Migraine. American Journal of Neuroradiology. 2017; 38 691-695.

[108] Serafini G, Pompili M, Innamorati M, Negro A, Fiorillo M, Lamis DA, et al. White matter hyperintensities and self-reported depression in a sample of patients with chronic headache. The Journal of Headache and Pain. 2012; 13: 661-667.

[109] Chong CD, Berisha V, Chiang CC, Ross K, Schwedt TJ. Less Cortical Thickness in Patients with Persistent Post-Traumatic Headache Compared with Healthy Controls: An MRI Study. Headache. 2018; 58: 53-61.

[110] Delic J, Alhilali LM, Hughes MA, Gumus S, Fakhran S. White Matter Injuries in Mild Traumatic Brain Injury and Posttraumatic Migraines: Diffusion Entropy Analysis. Radiology. 2016; 279: 859-866.

[111] Obermann M, Nebel K, Schumann C, Holle D, Gizewski ER, Maschke M, et al. Gray matter changes related to chronic posttraumatic headache. Neurology. 2009; 73: 978-983.

[112] Dumkrieger G, Chong CD, Ross K, Berisha V, Schwedt TJ. Static and dynamic functional connectivity differences between migraine and persistent post-traumatic headache: a resting-state magnetic resonance imaging study. Cephalalgia. 2019; 39: 13661381.

[113] Sarmento E, Moreira P, Brito C, Souza J, Jevoux C, Bigal M. Proton Spectroscopy in Patients with Post-Traumatic Headache Attributed to Mild Head Injury. Headache. 2009; 49: 1345-1352.

[114] Linnman C, Moulton EA, Barmettler G, Becerra L, Borsook D. Neuroimaging of the periaqueductal gray: state of the field. NeuroImage. 2012; 60: 505-522.

[115] Sherman KB, Goldberg M, Bell KR. Traumatic Brain Injury and Pain. Physical Medicine and Rehabilitation Clinics of North America. 2006; 17: 473-490.

[116] Smith DH, Chen X, Iwata A, Graham DI. Amyloid $\beta$ accumulation in axons after traumatic brain injury in humans. Journal of Neurosurgery. 2003; 98: 1072-1077.

[117] Moretti L, Cristofori I, Weaver SM, Chau A, Portelli JN, Grafman J. Cognitive decline in older adults with a history of traumatic brain injury. Lancet Neurology. 2012; 11: 1103-1112.

[118] Mofatteh M, Bullock SL. SnapShot: Subcellular mRNA Localization. Cell. 2017; 169: 178-178.e1.

[119] Mofatteh M. mRNA localization and local translation in neurons. AIMS neuroscience. 2020; 7: 299-310.

[120] Mofatteh M. Neurodegeneration and axonal mRNA transportation. American Journal of Neurodegenerative Disease. 2021; 10: $1-12$.

[121] Mofatteh M, Echegaray-Iturra F, Alamban A, Dalla Ricca F, Bakshi A, Aydogan MG. Autonomous clocks that regulate organelle biogenesis, cytoskeletal organization, and intracellular dynamics. Elife. 2021; 10: e72104.

[122] Schwedt TJ, Chong CD, Peplinski J, Ross K, Berisha V. Persistent post-traumatic headache vs. migraine: an MRI study demonstrating differences in brain structure. The Journal of Headache and Pain. 2017; 18: 87.

[123] Meier TB, Bellgowan PSF, Bergamino M, Ling JM, Mayer AR. Thinner Cortex in Collegiate Football Players with, but not Without, a Self-Reported History of Concussion. Journal of Neurotrauma. 2016; 33: 330-338.

[124] Sussman D, da Costa L, Chakravarty MM, Pang EW, Taylor MJ, Dunkley BT. Concussion induces focal and widespread neuromorphological changes. Neuroscience Letters. 2017; 650: 52-59.

[125] Tremblay S, De Beaumont L, Henry LC, Boulanger Y, Evans AC, Bourgouin $\mathrm{P}$, et al. Sports Concussions and Aging: A Neuroimag- ing Investigation. Cerebral Cortex. 2013; 23: 1159-1166.

[126] Chanraud S, Di Scala G, Dilharreguy B, Schoenen J, Allard M, Radat F. Brain functional connectivity and morphology changes in medication-overuse headache: Clue for dependence-related processes? Cephalalgia. 2014; 34: 605-615.

[127] Jia Z, Yu S. Grey matter alterations in migraine: a systematic review and meta-analysis. NeuroImage: Clinical. 2017; 14: 130-140

[128] Xue T, Yuan K, Cheng P, Zhao L, Zhao L, Yu D, et al. Alterations of regional spontaneous neuronal activity and corresponding brain circuit changes during resting state in migraine without aura. NMR in Biomedicine. 2013; 26: 1051-1058.

[129] Yang FC, Chou KH, Fuh JL, Lee PL, Lirng JF, Lin YY, et al. Altered hypothalamic functional connectivity in cluster headache: a longitudinal resting-state functional MRI study. Journal of Neurology Neurosurgery and Psychiatry. 2015; 86: 437-445.

[130] Baker VB, Eliasen KM, Hack NK. Lifestyle modifications as therapy for medication refractory post-traumatic headache (PTHA) in the military population of Okinawa. The Journal of Headache and Pain. 2018; 19: 113

[131] Kong J, White NS, Kwong KK, Vangel MG, Rosman IS, Gracely $\mathrm{RH}$, et al. Using fMRI to dissociate sensory encoding from cognitive evaluation of heat pain intensity. Human Brain Mapping. 2006; 27: 715-721.

[132] Chou KH, Yang FC, Fuh JL, Kuo CY, Wang YH, Lirng JF, et al. Bout-associated intrinsic functional network changes in cluster headache: A longitudinal resting-state functional MRI study. Cephalalgia. 2017; 37: 1152-1163.

[133] Michels L, Christidi F, Steiger VR, Sándor PS, Gantenbein AR, Landmann $G$, et al. Pain modulation is affected differently in medication-overuse headache and chronic myofascial pain - A multimodal MRI study. Cephalalgia. 2017; 37: 764-779.

[134] Zhang J, Su J, Wang M, Zhao Y, Yao Q, Zhang Q, et al. Increased default mode network connectivity and increased regional homogeneity in migraineurs without aura. The Journal of Headache and Pain. 2016; 17: 98

[135] Emerson NM, Zeidan F, Lobanov OV, Hadsel MS, Martucci KT, Quevedo AS, et al. Pain sensitivity is inversely related to regional grey matter density in the brain. Pain. 2014; 155: 566-573.

[136] Goffaux P, Girard-Tremblay L, Marchand S, Daigle K, Whittingstall K. Individual Differences in Pain Sensitivity Vary as a Function of Precuneus Reactivity. Brain Topography. 2014; 27: 366-374.

[137] Schwedt TJ, Chong CD. Correlations between brain cortical thickness and cutaneous pain thresholds are atypical in adults with migraine. PLoS ONE. 2014; 9: e99791.

[138] Chiapparini L, Grazzi L, Ferraro S, Mandelli ML, Usai S, Andrasik F, et al. Functional-MRI evaluation of pain processing in chronic migraine with medication overuse. Neurological Sciences. 2009; 30: S71-S74.

[139] Ferraro S, Grazzi L, Mandelli ML, Aquino D, Di Fiore D, Usai $S$, et al. Pain Processing in Medication Overuse Headache: a Functional Magnetic Resonance Imaging (fMRI) Study. Pain Medicine. 2012; 13: 255-262.

[140] Lamm C, Decety J, Singer T. Meta-analytic evidence for common and distinct neural networks associated with directly experienced pain and empathy for pain. NeuroImage. 2011; 54: 2492-2502.

[141] Moulton EA, Pendse G, Becerra LR, Borsook D. BOLD Responses in Somatosensory Cortices Better Reflect Heat Sensation than Pain. Journal of Neuroscience. 2012; 32: 6024-6031.

[142] Mofatteh M. Neurosurgery and artificial intelligence. AIMS Neuroscience. 2021; 8: 477-495.

[143] Denker PG, Perry GF. Postconcussion Syndrome in Compensation and Litigation; analysis of 95 cases with electroencephalographic correlations. Neurology. 1954; 4: 912-918.

[144] Levin HS, Grossman RG. Behavioral Sequelae of Closed Head Injury: A Quantitative Study. Archives of Neurology. 1978; 35: 720 727.

[145] Torres F, Shapiro SK. Electroencephalograms in Whiplash Injury: A Comparison of Electroencephalographic Abnormalities 
with Those Present in Closed Head Injuries. Archives of Neurology. 1961; 5: 28-35.

[146] Kwon M, Altin M, Duenas H, Alev L. The Role of Descending Inhibitory Pathways on Chronic Pain Modulation and Clinical Implications. Pain Practice. 2014; 14: 656-667.

[147] Abraira Victoria E, Ginty David D. The Sensory Neurons of Touch. Neuron. 2013; 79: 618-639.

[148] Shumskaya E, Andriessen TMJC, Norris DG, Vos PE. Abnormal whole-brain functional networks in homogeneous acute mild traumatic brain injury. Neurology. 2012; 79: 175-182.

[149] Abdel-Dayem HM, Abu-Judeh H, Kumar M, Atay S, Naddaf S, El-Zeftawy H, et al. SPECT Brain Perfusion Abnormalities in Mild or Moderate Traumatic Brain Injury. Clinical Nuclear Medicine. 1998; 23: 309-317.

[150] Amen DG, Newberg A, Thatcher R, Jin Y, Wu J, Keator D, et al. Impact of Playing American Professional Football on Long-Term Brain Function. The Journal of Neuropsychiatry and Clinical Neurosciences. 2011; 23: 98-106.

[151] Goldenberg G, Oder W, Spatt J, Podreka I. Cerebral correlates of disturbed executive function and memory in survivors of severe closed head injury: a SPECT study. Journal of Neurology Neurosurgery and Psychiatry. 1992; 55: 362-368.

[152] Stephens JA, Liu P, Lu H, Suskauer SJ. Cerebral Blood Flow after Mild Traumatic Brain Injury: Associations between Symptoms and Post-Injury Perfusion. Journal of Neurotrauma. 2018; 35: 241-248.

[153] Wang Y, West JD, Bailey JN, Westfall DR, Xiao H, Arnold TW, et al. Decreased Cerebral Blood Flow in Chronic Pediatric Mild TBI: an MRI Perfusion Study. Developmental Neuropsychology. 2015; 40: 40-44.

[154] Maugans TA, Farley C, Altaye M, Leach J, Cecil KM. Pediatric Sports-Related Concussion Produces Cerebral Blood Flow Alterations. Pediatrics. 2012; 129: 28-37.

[155] Barlow KM, Marcil LD, Dewey D, Carlson HL, MacMaster FP, Brooks BL, et al. Cerebral Perfusion Changes in Post-Concussion Syndrome: A Prospective Controlled Cohort Study. Journal of Neurotrauma. 2017; 34: 996-1004.

[156] Evans RW. Post-traumatic headaches. Neurologic Clinics. 2004; 22: 237-249.

[157] Zeeberg P, Olesen J, Jensen R. Efficacy of Multidisciplinary Treatment in a Tertiary Referral Headache Centre. Cephalalgia. 2005; 25: 1159-1167.

[158] Larsen EL, Ashina H, Iljazi A, Al-Khazali HM, Seem K, Ashina $\mathrm{M}$, et al. Acute and preventive pharmacological treatment of posttraumatic headache: a systematic review. The Journal of Headache and Pain. 2019; 20: 98.

[159] Riechers RG, Walker MF, Ruff RL. Post-traumatic headaches. Handbook of Clinical Neurology. 2015; 128: 567-578.

[160] Chan S, Kurowski B, Byczkowski T, Timm N. Intravenous migraine therapy in children with posttraumatic headache in the ED The American Journal of Emergency Medicine. 2015; 33: 635639.

[161] Capi M, Pomes LM, Andolina G, Curto M, Martelletti P, Lionetto L. Persistent Post-Traumatic Headache and Migraine: PreClinical Comparisons. International Journal of Environmental Research and Public Health. 2020; 17: 2585.

[162] Friedman BW, Babbush K, Irizarry E, White D, John Gallagher E. An exploratory study of IV metoclopramide + diphenhydramine for acute post-traumatic headache. The American Journal of Emergency Medicine. 2018; 36: 285-289.

[163] Seeger TA, Orr S, Bodell L, Lockyer L, Rajapakse T, Barlow KM. Occipital Nerve Blocks for Pediatric Posttraumatic Headache: A Case Series. Journal of Child Neurology. 2015; 30: 1142-1146.

[164] Pompili M, Innamorati M, Lamis DA, Serafini G, Ricci F, Migliorati $\mathrm{M}$, et al. Depression and insomnia are independently associated with satisfaction and enjoyment of life in medicationoveruse headache patients. The International Journal of Psychiatry in Medicine. 2016; 51: 442-455.

[165] Heyer GL, Idris SA. Does Analgesic Overuse Contribute to
Chronic Post-traumatic Headaches in Adolescent Concussion Patients? Pediatric Neurology. 2014; 50: 464-468.

[166] Pinchefsky E, Dubrovsky AS, Friedman D, Shevell M. Part IEvaluation of Pediatric Post-traumatic Headaches. Pediatric Neurology. 2015; 52: 263-269.

[167] Haas D. Chronic Post-Traumatic Headaches Classified and Compared with Natural Headaches. Cephalalgia. 1996; 16: 486-493.

[168] Baandrup L, Jensen R. Chronic Post-Traumatic Headache - A Clinical Analysis in Relation to the International Headache Classification 2nd Edition. Cephalalgia. 2005; 25: 132-138.

[169] Friedman BW, Esses D, Solorzano C, Dua N, Greenwald P, Radulescu R, et al. A Randomized Controlled Trial of Prochlorperazine Versus Metoclopramide for Treatment of Acute Migraine. Annals of Emergency Medicine. 2008; 52: 399-406.

[170] Kabbouche MA, Vockell AB, LeCates SL, Powers SW, Hershey AD. Tolerability and Effectiveness of Prochlorperazine for Intractable Migraine in Children. Pediatrics. 2001; 107: e62-e62.

[171] Leung S, Bulloch B, Young C, Yonker M, Hostetler M. Effectiveness of Standardized Combination Therapy for Migraine Treatment in the Pediatric Emergency Department. Headache. 2013; 53: 491-197.

[172] Trottier ED, Bailey B, Lucas N, Lortie A. Prochlorperazine in children with migraine: a look at its effectiveness and rate of akathisia. The American Journal of Emergency Medicine. 2012; 30: 456-463.

[173] Weiss HD, Stern BJ, Goldberg J. Post-Traumatic Migraine: Chronic Migraine Precipitated by Minor Head or Neck Trauma. Headache. 1991; 31: 451-456.

[174] Lippert-Grüner M. Botulinum toxin in the treatment of posttraumatic headache - case study. Neurologia i Neurochirurgia Polska. 2012; 46: 591-594.

[175] Herd A, Ludwig L. Relief of posttraumatic headache by intravenous chlorpromazine. The Journal of Emergency Medicine. 1994; 12: 849-851.

[176] McBeath JG, Nanda A. Use of Dihydroergotamine in Patients with Postconcussion Syndrome. Headache. 1994; 34: 148-151.

[177] Packard RC. Treatment of Chronic Daily Posttraumatic Headache with Divalproex Sodium. Headache. 2000; 40: 736-739.

[178] Friedman MH, Peterson SJ, Frishman WH, Behar CF. Intraoral Topical Nonsteroidal Antiinflammatory Drug Application for Headache Prevention. Heart Disease. 2002; 4: 212-215.

[179] Gawel M, Rothbart P. Occipital Nerve Block in the Management of Headache and Cervical Pain. Cephalalgia. 1992; 12: 9-13.

[180] O'Sullivan C, Froyman C. Nortriptyline safer than amitriptyline? Canadian family physician Medecin de famille canadien. 2018; 64: 634-636.

[181] Dubrovsky AS, Friedman D, Kocilowicz H. Pediatric PostTraumatic Headaches and Peripheral Nerve Blocks of the Scalp: A Case Series and Patient Satisfaction Survey. Headache. 2014; 54: 878-887.

[182] Gurr B, Coetzer BR. The effectiveness of cognitive-behavioral therapy for post-traumatic headaches. Brain Injury. 2005; 19: 481491.

[183] Lambru G, Benemei S, Andreou AP, Luciani M, Serafini G, van den Brink AM, et al. Position Paper on Post-Traumatic Headache: the Relationship between Head Trauma, Stress Disorder, and Migraine. Pain and Therapy. 2021; 10: 1-13.

[184] Vos T, Allen C, Arora M, Barber RM, Bhutta ZA, Brown A, et al. Global, regional, and national incidence, prevalence, and years lived with disability for 310 diseases and injuries, 1990-2015: a systematic analysis for the Global Burden of Disease Study 2015. The Lancet. 2016; 388: 1545-1602.

[185] Mofatteh M. Risk factors associated with stress, anxiety, and depression among university undergraduate students. AIMS Public Health. 2021; 8: 36-65.

[186] McKinlay A, Grace R, Horwood J, Fergusson D, MacFarlane M. Adolescent Psychiatric Symptoms Following Preschool Childhood Mild Traumatic Brain Injury: Evidence from a birth cohort. Journal of Head Trauma Rehabilitation. 2009; 24: 221-227. 
[187] Bryant RA, Marosszeky JE, Crooks J, Baguley IJ, Gurka JA. Interaction of Posttraumatic Stress Disorder and Chronic Pain following Traumatic Brain Injury. The Journal of Head Trauma Rehabilitation. 1999; 14: 588-594.

[188] Stein MB, Jain S, Giacino JT, Levin H, Dikmen S, Nelson LD, et al. Risk of Posttraumatic Stress Disorder and Major Depression in Civilian Patients after Mild Traumatic Brain Injury. JAMA Psychiatry. 2019; 76: 249-258.

[189] Vasterling JJ, Jacob SN, Rasmusson A. Traumatic Brain Injury and Posttraumatic Stress Disorder: Conceptual, Diagnostic, and Therapeutic Considerations in the Context of Co-Occurrence. The Journal of Neuropsychiatry and Clinical Neurosciences. 2018; 30: 91-100.

[190] Halterman CI, Langan J, Drew A, Rodriguez E, Osternig LR, Chou L, et al. Tracking the recovery of visuospatial attention deficits in mild traumatic brain injury. Brain. 2006; 129: 747-753.

[191] Eccleston C, Crombez G. Pain demands attention: A cognitiveaffective model of the interruptive function of pain. Psychological Bulletin. 1999; 125: 356-66.
[192] Legrain V, Damme SV, Eccleston C, Davis KD, Seminowicz DA, Crombez G. A neurocognitive model of attention to pain: Behavioral and neuroimaging evidence. Pain. 2009; 144: 230-232.

[193] Collett GA, Song K, Jaramillo CA, Potter JS, Finley EP, Pugh MJ. Prevalence of Central Nervous System Polypharmacy and Associations with Overdose and Suicide-Related Behaviors in Iraq and Afghanistan War Veterans in VA Care 2010-2011. Drugs-Real World Outcomes. 2016; 3: 45-52.

[194] Morgan M, Lockwood A, Steinke D, Schleenbaker R, Botts S. Pharmacotherapy Regimens Among Patients with Posttraumatic Stress Disorder and Mild Traumatic Brain Injury. Psychiatric Services. 2012; 63: 182-185.

[195] D’Amico D, Tepper SJ, Guastafierro E, Toppo C, Leonardi M, Grazzi L, et al. Mapping Assessments Instruments for Headache Disorders against the ICF Biopsychosocial Model of Health and Disability. International Journal of Environmental Research and Public Health. 2020; 18: 246. 